\title{
Comparative Study between No Mesh Inguinal Hernia Repair (Desarda Technique) and Mesh Hernioplasty and its Outcome
}

Dr. Tejas Anand Kamat ${ }^{1 *}$, Dr. Jeevan V Shinde ${ }^{2}$

\author{
${ }^{1}$ PG resident, Department of General Surgery, Smt Kashibai Navale Medical College and General Hospital, S.No, 49/1, Mumbai Pune Bypass Rd, \\ Narhe, Pune, Maharashtra 411041, India \\ ${ }^{2}$ Professor, Department of General Surgery, Smt Kashibai Navale Medical College and General Hospital, S.No, 49/1, Mumbai Pune Bypass Rd, Narhe,
} Pune, Maharashtra 411041, India

DOI: $10.36348 /$ sjmps.2020.v06i01.007

| Received: 06.01.2020 | Accepted: 13.01.2020 | Published: 17.01.2020

*Corresponding author: Dr. Tejas Anand Kamat

\section{Abstract}

Background: Inguinal hernia is the most common surgical disorder occurring in young as well as elder males worldwide. Management wise there are many surgeries available in both tissue-based hernia repair as well as commonly practised prolene mesh inguinal hernia repair. New technique has developed, desarda hernia repair, is the tissue-based hernia repair in which, an un-detached strip of external oblique aponeurosis is used to repair the posterior wall of inguinal canal. This study compares the outcome of both desarda repair and lictenstein mesh hernia repair. Methods: Hospital based interventional study included 100 patients diagnosed with inguinal hernia and were divided into two groups, D (50 patients) for desarda technique and L (50 patients) for lictenstein repair. Outcomes measured were post operative complications as seroma, hematoma, orchitis, early and late postoperative pain, chronic pain and last was the recurrence. Hospital stay was also taken into consideration and follow up was done on day 7, 1 month, 6 months and 1 year after surgery. Results: During follow up, 10 patients suffered from chronic pain in lictenstein group compared to 5 patients in desarda group which was not significant $(\mathrm{p}=0.262)$. 1 Recurrence was seen both groups $(\mathrm{p}=1)$. Seroma was seen in 2 patients in desarda and nil in L group whereas hematoma was seen more in L group. Conclusion: Results were comparable in both the groups, desarda being a new technique can be used in young patients to avoid complications most probably seen in mesh hernia repair.

Keywords: Desarda, Lichtenstein, seroma, hematoma, recurrence, polydioxanone violet.

Copyright @ 2020: This is an open-access article distributed under the terms of the Creative Commons Attribution license which permits unrestricted use, distribution, and reproduction in any medium for non-commercial use (NonCommercial, or CC-BY-NC) provided the original author and source are credited.

\section{INTRODUCTION}

Inguinal hernia repair is one of the most common operations undertaken in routine surgical practice. It generally carries a very low risk of major adverse sequelae.The incidence and prevalence of inguinal hernia are not calculated yet. Risk of inguinal hernia in men is about $27 \%$ and $3 \%$ in females in their life time [1].

As per European Hernia Society (EHS) guidelines published in 2009, prolene mesh-based procedures ie. Lichtenstein technique and laparoscopic methods are preferred for treatment of symptomatic inguinal hernia in adult men while the Shouldice tissue based hernia repair technique is considered the best non-mesh repair method.

Lictenstein technique, nowadays, is the most preferred and most popularly used technique for inguinal hernia repair due to its minimal perioperative morbidity and very low recurrence [2].

Incidence of chronic groin pain after lichtenstein technique has increased over years mainly due to implanted mesh. Complications such as seroma, hematoma, foreign body sensation has increased over years in respect to lictenstein hernia repair. Migration of mesh is also deadly complications faced post hernia repair [3]. Hence, yet to know all aspects of hernia surgery, tissue based technique can be a better surgical approach compared to globally practised lictenstein technique.

Hence, this study includes all the aspects of desarda repair as well as lictenstein repair and their outcomes to compare. 


\section{Aims And ObJectives Of STUdy}

- To try technique of inguinal hernia repair using external oblique aponeurosis strip as described by Dr. Desarda in our cases.

- To study the complications of this type of hernia repair like Hematoma, seroma, orchitis, postoperative pain.

- To study the recurrence rate and causes of recurrences in our cases.

- To compare our results with series of Desarda technique and Lictenstein tension free mesh hernia repair.

\section{Materials AND MethodS}

Study Design: Hospital based interventional study.

\section{Source of Data}

100 patients diagnosed with inguinal hernia during the period of November 2017 to November 2019 at Smt kashibai navale medical college and general hospital, pune.

\section{INCLUSION CRITERIA}

- Primary inguinal hernia (Both direct and indirect type)

- Male adults

- Signed informed consent

- Good condition of external oblique aponeurosis (assessed during surgery)

\section{ExClusion Criteria}

- Age $<18$ years

- Recurrent hernia

- Incarcerated hernia

- Strangulated hernia

- Infection at groin site

- No consent

\section{Informed Written Consent}

All patients will be made to sign an informed written consent prior to the procedure and an information sheet, stating knowledge of their case findings, clinical data and treatment outcome being put to use for medical research on grounds of nondisclosure of their names and personal details.

A through history was taken in all patients. A detailed clinical examination was done. The routine investigation was also done. The patients underwent surgery and post-operative course was noted.

A comparative study between the 100 patients undergoing open mesh and Desarda repair was done based on randomization.
Just before taking the patient for surgery, sealed envelop (written mesh/ desarda) was opened and thus randomized. Randomized patients were followed for one year duration post-operatively and outcomes compared.

All the information was taken in a proforma, designed for the study. Important data pertaining to each case is shown in the master chart.

Ethical clearance was taken from the ethical committee prior to conducting the study.

\section{Technique of Desarda Repair}

Inguinal Incision is taken, deepened in layer to expose external oblique aponeurosis [EOA]. As far as possible, a thin, filmy fascial layer covering EOA is kept intact. EOA is cut in line with upper crux of superficial ring. The sac is excised and transfixed in indirect hernias and is inverted in direct hernias.

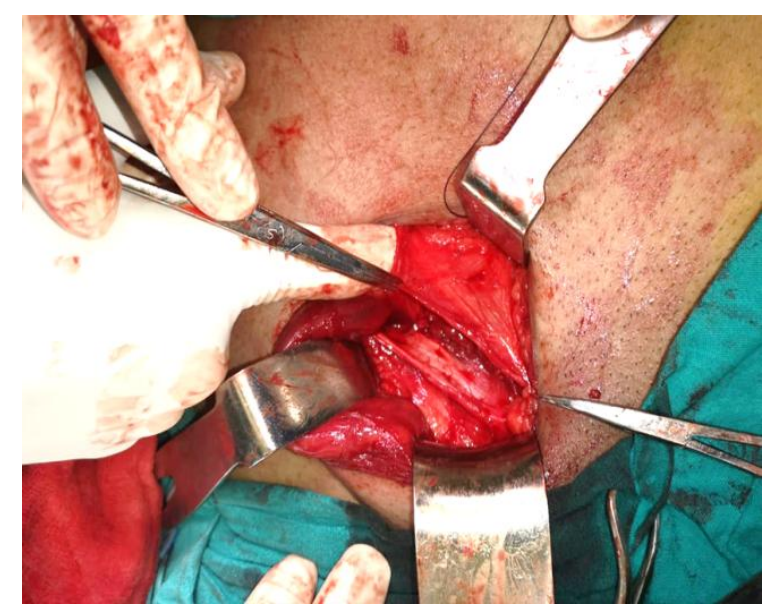

Fig-1: Upper lip of EOA sutured to inguinal ligament

The upper leaf of EOA is sutured with incurved inguinal ligament from pubic tubercle to internal abdominal ring using 2-0 Monofilament polydioxanone violet with continuous interlocking fashion as shown in the Fig-1.

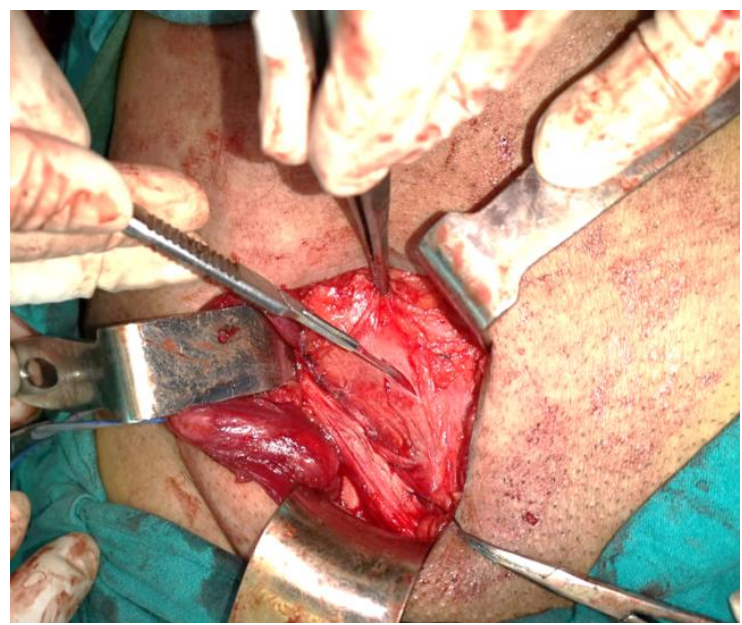

Fig-2: Splitting incision over EOA 
Splitting incision is made in this sutured upper leaf, partially separating a strip $2 \mathrm{~cm}$ wide. This incision is extended medially upto pubic symphisis and $1-2 \mathrm{~cm}$ beyond the internal abdominal ring laterally. The medial insertion and lateral continuation of this strip is kept intact as shown in Fig-2.

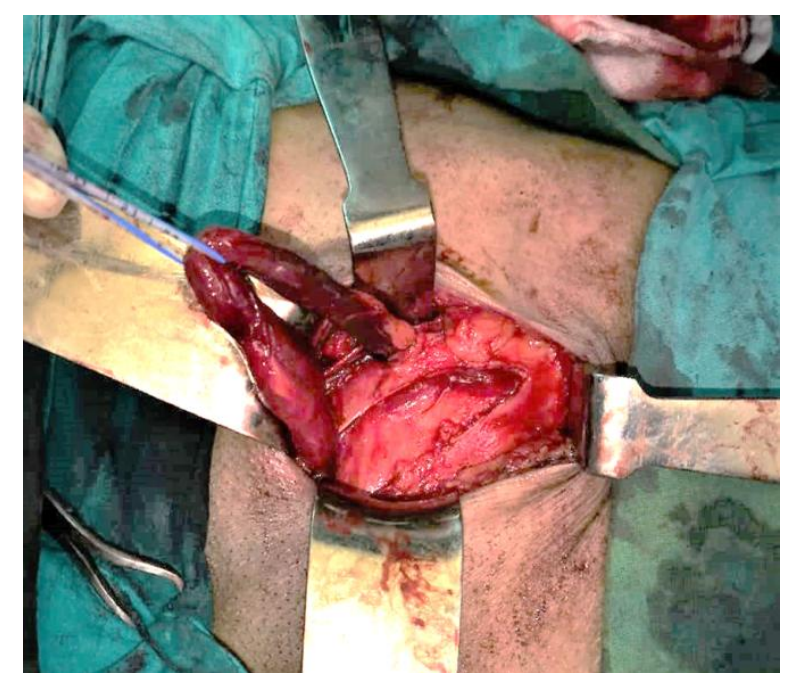

Fig-3: Sutured upper free border of strip to conjoint tendon

The upper free border of this strip is now sutured to internal oblique with Monofilament polydioxanone violet continuous interlocking fashion all along its length as shown in Fig-3. This will result in the strip of the EOA being placed behind the cord to form a new posterior wall of inguinal canal.

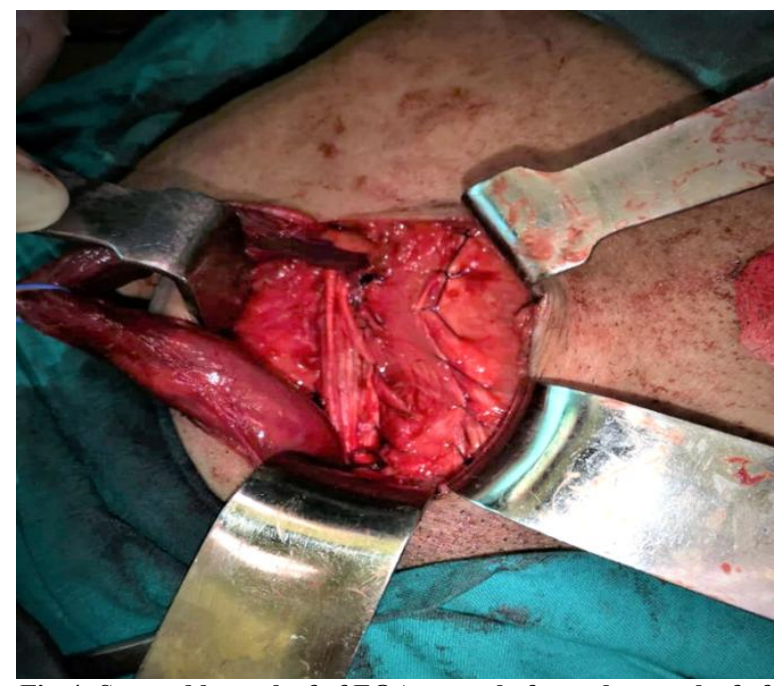

Fig-4: Sutured lower leaf of EOA to newly formed upper leaf of EOA

Now the spermatic cord is placed in the inguinal canal and the lower leaf of EOA is sutured to newly formed upper leaf of EOA in front of the cord with absorbable continuous interlocking sutures Fig-4.

Undermining of the newly formed upper leaf on both its surfaces and excision of bulky cremasteric muscle if required facilitates its approximation to lower leaf. This is followed by routine closure of superficial fascia and the skin.

\section{RESUlTS}

Total 100 patients were included in this study, 50 were operated via Lichtenstein technique and other 50 by desarda technique, results were as follows:

\section{Patients Demography}

Table-1: Age distribution in both the groups

\begin{tabular}{|l|l|l|}
\hline GROUPS & NUMBER & MEAN AGE \\
\hline DESARDA & 50 & 33.24 \\
\hline LICHTENSTEIN & 50 & 33.56 \\
\hline TOTAL & 100 & 33.40 \\
\hline
\end{tabular}

\section{AGE DISTRIBUTION}

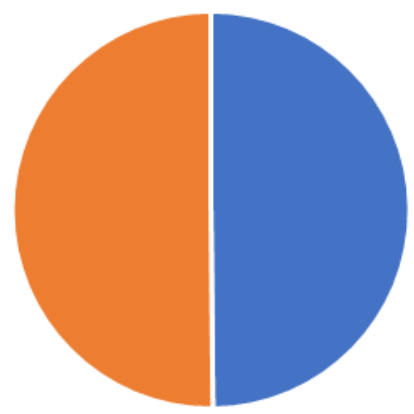

- DESARDA - LICHTENSTEIN ㅁ

Table-2: Sex distribution in both the groups

\begin{tabular}{|l|l|l|}
\hline GROUPS & SEX - MALE & TOTAL \\
\hline DESARDA & 50 & 50 \\
\hline LICHTENSTEIN & 50 & 50 \\
\hline TOTAL & 100 & 100 \\
\hline
\end{tabular}

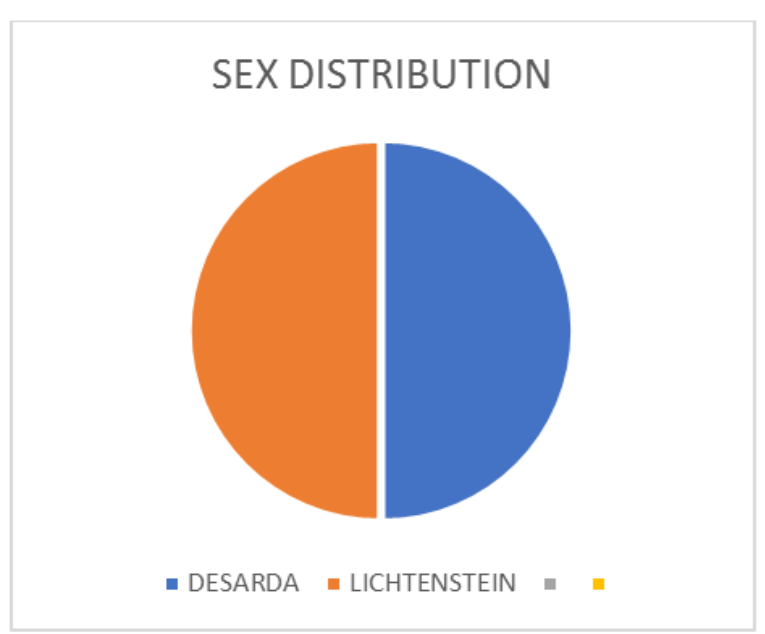


Tejas Anand Kamat \& Jeevan V Shinde; Saudi J Med Pharm Sci, Jan., 2020; 6(1): $42-49$

Table-3: Side distribution as per groups

\begin{tabular}{|l|l|l|l|l|l|}
\hline \multirow{2}{*}{ GROUPS } & \multicolumn{2}{|l|}{ SIDE } & TOTAL & \multirow{2}{*}{ SIGNIFICANCE } \\
\cline { 2 - 5 } & BILATERAL & LEFT & RIGHT & & \\
\hline DESARDA & 10 & 20 & 20 & 50 & P=0.905 \\
LICHTENSTEIN & 10 & 18 & 22 & 50 & (Not Significant) \\
\hline TOTAL & 20 & 38 & 42 & 100 & \\
\hline \multicolumn{2}{|l|}{ Pearson Chi square test is used for comparison in both groups, Chi value is 0.201 } \\
\hline
\end{tabular}

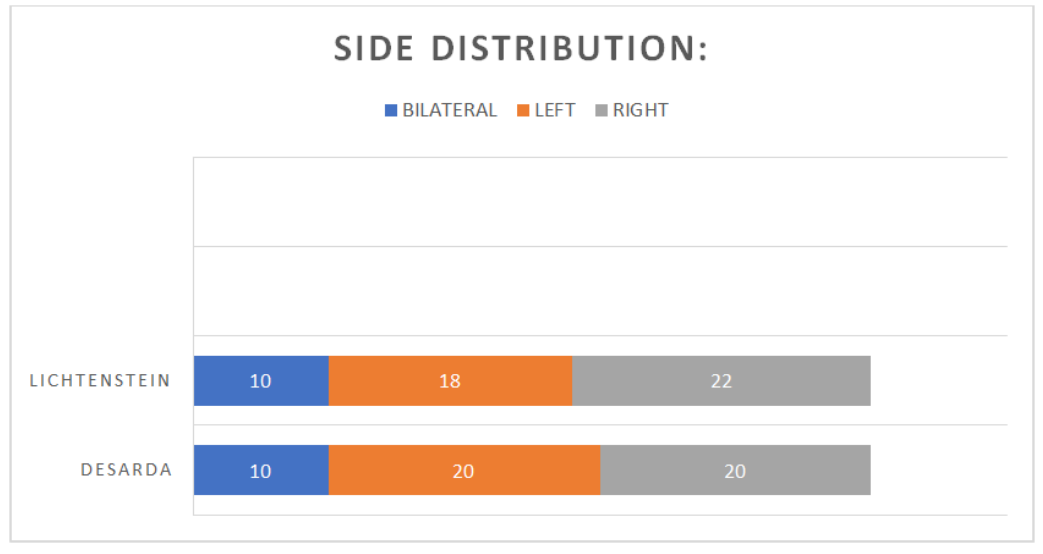

\section{DISTRIBUTION AS PER COMPLICATIONS}

Table-4: SEROMA formation in both the groups

\begin{tabular}{|l|l|l|l|l|}
\hline \multirow{2}{*}{ GROUPS } & \multicolumn{2}{|l|}{ SEROMA } & \multirow{2}{*}{ TOTAL } & SIGNIFICANCE \\
\cline { 2 - 4 } & NO & YES & & \\
\hline DESARDA & 48 & 2 & 50 & $\begin{array}{l}\text { P=0.495 } \\
\text { (Not significant) }\end{array}$ \\
\hline LICHTENSTEIN & 50 & 0 & 50 & \\
\hline TOTAL & 98 & 2 & 100 & \\
\hline \multicolumn{2}{|l|}{ Fishers exact test is used for comparison in both groups. } \\
\hline
\end{tabular}

Table-5: HEMATOMA formation in both the groups

\begin{tabular}{|c|c|c|c|c|}
\hline \multirow[t]{2}{*}{ GROUPS } & \multicolumn{2}{|c|}{ НЕМАТОМА } & \multirow[t]{2}{*}{ TOTAL } & \multirow[t]{2}{*}{ SIGNIFICANCE } \\
\hline & NO & YES & & \\
\hline DESARDA & 50 & 0 & 50 & \multirow{3}{*}{$\begin{array}{l}\mathrm{P}=0.242 \\
\text { (Not significant) }\end{array}$} \\
\hline LICHTENSTEIN & 47 & 3 & 50 & \\
\hline TOTAL & 97 & 3 & 100 & \\
\hline
\end{tabular}

Table-6: ORCHITIS in both the groups

\begin{tabular}{|c|c|c|c|c|}
\hline \multirow[t]{2}{*}{ GROUPS } & \multicolumn{2}{|c|}{ ORCHITIS } & \multirow[t]{2}{*}{ TOTAL } & \multirow[t]{2}{*}{ SIGNIFICANCE } \\
\hline & NO & YES & & \\
\hline DESARDA & 50 & 0 & 50 & \multirow{3}{*}{$\begin{array}{l}\mathrm{P}=1 \\
\text { (Not significant) }\end{array}$} \\
\hline LICHTENSTEIN & 49 & 1 & 50 & \\
\hline TOTAL & 99 & 1 & 100 & \\
\hline
\end{tabular}

Table-7: Early post op pain

\begin{tabular}{|c|c|c|c|c|}
\hline \multirow[t]{2}{*}{ Groups } & \multicolumn{2}{|c|}{ Early Post Op Pain(<3 Days) } & \multirow[t]{2}{*}{ Total } & \multirow[t]{2}{*}{ Significance } \\
\hline & NO & YES & & \\
\hline DESARDA & 49 & 1 & 50 & \multirow{3}{*}{$\begin{array}{l}\mathrm{P}=0.004 \\
(\mathrm{SIGNIFICANT})\end{array}$} \\
\hline LICHTENSTEIN & 39 & 11 & 50 & \\
\hline TOTAL & 88 & 12 & 100 & \\
\hline
\end{tabular}


Table-8: Late post op pain

\begin{tabular}{|l|l|l|l|l|}
\hline \multirow{2}{*}{ Groups } & \multicolumn{2}{|l|}{$\begin{array}{l}\text { Late Post Op Pain } \\
\text { (>3 Days) }\end{array}$} & Total & Significance \\
\cline { 2 - 3 } & NO & YES & & \\
\hline DESARDA & 48 & 2 & 50 & $\mathrm{P}=0$ \\
\hline LICHTENSTEIN & 34 & 16 & 50 & (Significant) \\
\hline TOTAL & 82 & 18 & 100 & \\
\hline
\end{tabular}

Fishers Exact test is used for comparison of both the groups.

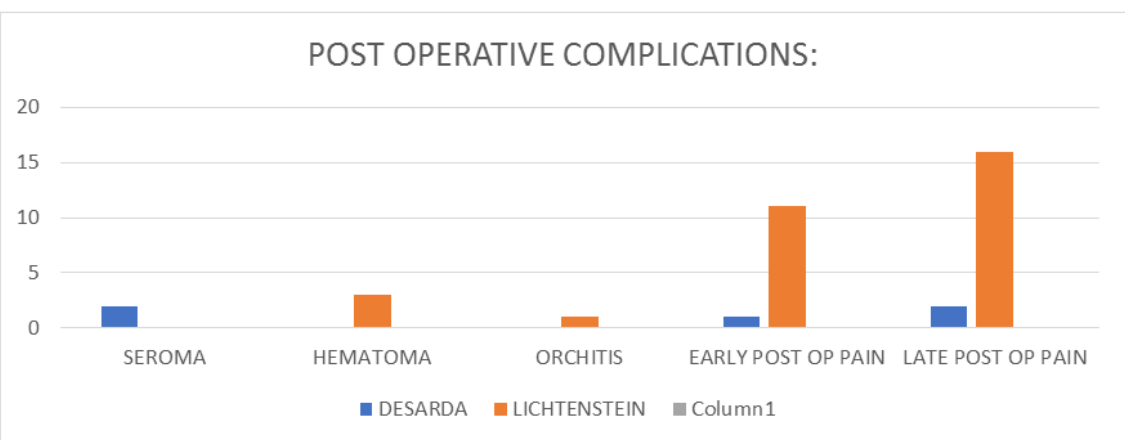

Table-9: Distribution as Per Hospital Stay

\begin{tabular}{|l|l|l|l|l|}
\hline \multirow{2}{*}{ GROUPS } & \multicolumn{2}{|c|}{ HOSPITAL STAY } & TOTAL & SIGNIFICANCE \\
\cline { 2 - 4 } & $\langle\mathbf{3}$ DAYS & $\mathbf{> 3}$ DAYS & & \\
\hline DESARDA & 47 & 3 & 50 & $\mathrm{P}=0.318$ \\
\hline LICHTENSTEIN & 43 & 7 & 50 & (Not significant) \\
\hline TOTAL & 90 & 10 & 100 & \\
\hline Fishers Exact test is used for comparison in both the groups. \\
\hline
\end{tabular}

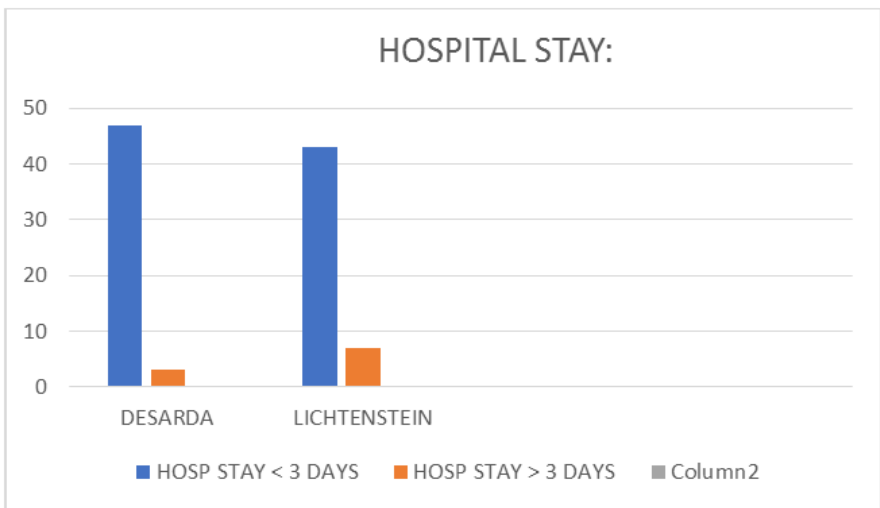

Table-10: Distribution as Per Chronic Pain

\begin{tabular}{|l|l|l|l|l|}
\hline \multirow{2}{*}{ GROUPS } & \multicolumn{2}{|l|}{ CHRONIC PAIN } & TOTAL & \multirow{2}{*}{ SIGNIFICANCE } \\
\cline { 2 - 4 } & NO & YES & & \\
\hline DESARDA & 45 & 5 & 50 & P $=0.262$ \\
\hline LICHTENSTEIN & 40 & 10 & 50 & (Not significant) \\
\hline TOTAL & 85 & 15 & 100 & \\
\hline \multicolumn{7}{|l}{ Fishers exact test is used for comparison in both the groups. } \\
\hline
\end{tabular}

Table-11: Distribution as Per Recurrance

\begin{tabular}{|l|l|l|l|l|}
\hline \multirow{2}{*}{ GROUPS } & \multicolumn{2}{|l|}{ RECURRANCE } & TOTAL & \multirow{2}{*}{ SIGNIFICANCE } \\
\cline { 2 - 4 } & NO & YES & & \\
\hline DESARDA & 49 & 1 & 50 & $\mathrm{P}=1$ \\
\hline LICHTENSTEIN & 49 & 1 & 50 & (Not significant) \\
\hline TOTAL & 98 & 2 & 100 & \\
\hline \multicolumn{4}{|l|}{ Fishers exact test is used for comparison in both the groups. } \\
\hline
\end{tabular}




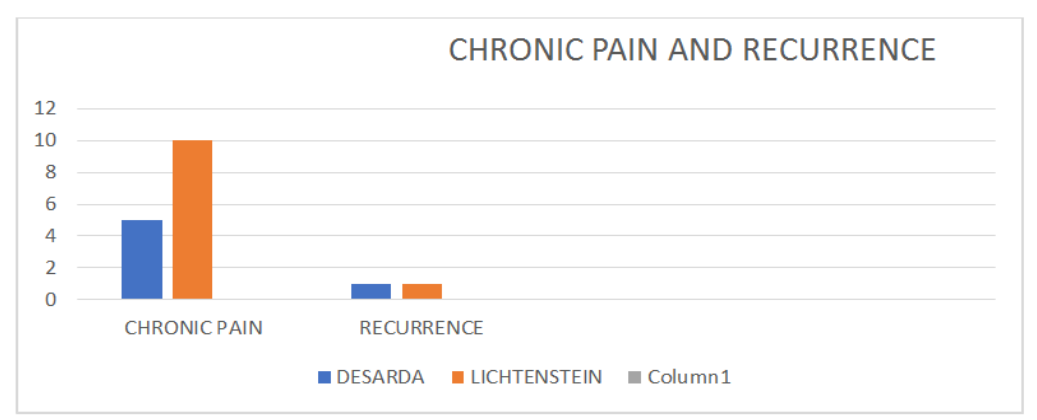

\section{DISCUSSION}

In this 2 year study, we encountered significant difference comparing early and late postoperative pain in both the groups where-as there was no other significant difference comparing other factors. Currently, the results of hernia treatment, even as per the EHS guidelines, vary from moderate to excellent. The mean recurrence rate for the standard Lichtenstein procedure is $1 \%$ in hernia-specialized centers but is higher in community hospitals (about 4\%), and the reported rate is even $18 \%$ in some studies [4]. The data published for other mesh techniques vary:

- 0 to $4.2 \%$ recurrences for Prolene Hernia System (PHS) [5],

- 0 to $4 \%$ for Rutkow [6],

- $\quad 1.6$ to $19.0 \%$ for the (TAPP) [4]

The frequency of postoperative complications reported in literature is between 15 and $28 \%$ [29, 30]. When active postoperative monitoring is done, the frequency can reach upto $50 \%[4]$.

The most frequently reported complications were seroma, hematoma, chronic pain, surgical-site infection, and recurrence [7]. Death and major worsening of operated patients' quality of life were rare but were reported too $[7,8]$. These data suggest the need for further investigation of clinical problem.

Globally many studies are ongoing to improve the technique of inguinal hernia repair. Commercially avail-able lightweight prolene meshes, composed meshes, and other biologic prostheses are being tested. The scientific work of optimizing hernia surgery as well as reducing the number of complications is still in progress. Also tissue-based techniques are not out of the realm of consideration in hernia field.

This Desarda technique for inguinal hernia repair is a novel tissue-based method. Despite the objections emerged by some authors $[9,10]$, application of the external oblique aponeurosis in form of undetached strip (which makes posterior wall of inguinal canal stronger) is being established as new concept in tissue-based hernia repair. The technique is original, different, and new from historical methods using the external oblique aponeurosis, proposed by McArthur [11] and Andrews or Zimmermann [12].

This novel repair method completes the principles of "no tension" presented by Lichtenstein. The aponeurotic strip is displaced from anterior to posterior wall of inguinal canal without additional tension at the posterior wall. The concept of undetached, mobile aponeurotic strip that "physiologically" strengthens the posterior wall of inguinal canal is original and exciting [13, 14]. When considering Desarda as "dynamic enforcement" of inguinal canal's posterior wall, the Lichtenstein can be known as "prosthetic enforcement." The author of first method hypothesizes that a naturally displaced and mobile aponeurotic strip is far more "physiological" than scar tissue produced around a synthetic prosthesis for creating a mechanism against re herniation.

The Shouldice technique, which is still accepted worldwide, is tissue-based as well. Till date, there is no such comparison study on aponeurotic tissue and the transversalis fascia. The properties of inguinal connective tissue are being generalised mainly from studies on transversalis fascia. It should be known that the genetic as well as the biochemical changes are found in only 20 to $30 \%$ patients. Assuming that there are about 15 to $20 \%$ recurrences after some tissue-based techniques, $80 \%$ of patients survive without recurrence. It might be postulated that there is a population of hernia patients in whom tissue-based techniques could be used safely.

In our study there was no statistical significant difference encountered comparing complications in both the groups such as seroma, hematoma, orchitis etc. The recurrence rate in both the groups were equal ie one in each group. In the Desarda group, the recurrence was obviously due to technical error. The aponeurotic strip created was big in length, resulting in a newly formed big deep inguinal ring and hence re-herniation. In the Lichtenstein group, the recurrence was typical. This additionally supports the idea that surgical technique is crucial for good final result.

Although chronic pain is defined as lasting more than 3 months by International Association for the Study of Pain [15],in our study we defined chronic pain 
as pain lasting for more than 6 months due to the use of prolene mesh for hernia repair and taking into account the fact that inflammatory response to foreign material may last longer. This approach has been used by many other authors $[16,17]$ and is recommended in the latest publications [18].

In our study, 5 patients from desarda group experienced chronic pain while 10 patients from Lichtenstein group experienced the same, probably due to nerve entrapment following mesh hernioplasty. This difference was not statistically significant too.

Whereas comparing the parameters of early and late post-operative pain which was considered as less than 3 days post-operative and more than 3 days post-operative respectively, in desarda group, only one patient experienced early post-operative pain as compared to 11 from lictenstein group which is statistically significant. Late post-operative pain, in desarda group was experienced by only 2 patients whereas from lictenstein group, 16 patients experienced pain which is statistically significant.

Pain was monitored with help of visual analog scale in both the groups. In comparison with hospital stay, there was no statistically significant result noted

The higher ratio of hematoma and seroma after use of the Lichtenstein method can be explained by the influence of the prolene mesh on surrounding tissues. This is consistent with other studies and the known side effect of polypropylene on tissue [19, 20]. Foreign body sensation and abdominal wall stiffness were expressed equally by both the groups and the results are within the range (4.5-43.8\%) reported by other authors for mesh techniques [21, 22]. Surprisingly, the mesh-related sensations were experienced similarly by patients from both groups and did not change even after the participants were informed of the technique used after 2 years of follow-up.

Mitura and Roman-czuk have published the results of a 6-month follow-up study of the Desarda and Lichtenstein approaches. They observed no recurrence, and pain after 6 months was comparable in the two groups (VAS scores were 8 vs. 11 inthe Desarda and Lichtenstein groups, respectively; $\mathrm{p}=0.691$ ).

Situma et al., [23] presented their results of Desarda versus modified Bassini inguinal hernia repair, concluding that there was no difference between these techniques in regard to pain and return to normal activity.

Other results, published by Desarda and his group, were based on a comparison of his technique and the Lichtenstein technique [24]. There was no recurrence in 269 Desarda group patients and 1.97\% recurrence in 225 mesh group patients; $6.49 \%$ of patients operated in mesh group and zero patients in the
Desarda group complained of chronic pain at 1 year after surgery. In literature, despite some methodologic inadequacies in presented articles, the Desarda method merits more attention and more efficacy compared to lictenstein group.

Paradoxically, in the modern world the cost of surgery becomes the real issue. The cost of inguinal hernia treatment, is not insignificant, however, especially in developing countries in Africa and Asia. One advantage of Desarda technique is its very low cost. That is why many authors published articles recently demonstrated an interest in this technique [23, 25-27]. The cost of the Desarda operation is low because a synthetic prosthesis is not used. The price of composite mesh can be a big task in developing countries. Not only the economical issues but the use of synthetic material is still controversial in young patients. The effect of polyproplylene placement inside human organism for a lifetime is still unknown. Also, data are appearing about sexual impairment after mesh implantation; and hence many surgeons try to avoid mesh prostheses for hernia treatment in young patients. Also, Desarda is a tissue-based technique, which can be used in a contaminated operative field, usually seen for strangulated hernias.

\section{Conclusion}

This randomised controlled trial confirmed that the results of inguinal hernia repair with the Desarda technique are similar to the results after standard Lichtenstein operations over a 2-year time period in comparison with recurrence, chronic pain, surgical complcations, hospital stay etc.

Whereas comparing early and late postoperative pain as well as cost effectiveness is significantly better seen in desarda technique.

Based on these results, this technique has the potential to enlarge the number of tissue-based methods available to treat groin hernias.

The most important indications for use of the Desarda technique include alternative repair in young adults, in contaminated operative fields, in the presence of economical issues, or if a patient is not willing to use mesh.

\section{REFERENCES}

1. Primatesta, P., \& Goldacre, M. J. (1996). Inguinal hernia repair: incidence of elective and emergency surgery, readmission and mortality. International journal of epidemiology, 25(4), 835-839.

2. Simons, M. P., Aufenacker, T., Bay-Nielsen, M., Bouillot, J. L., Campanelli, G., Conze, J., ... \& Kukleta, J. (2009). European Hernia Society guidelines on the treatment of inguinal hernia in adult patients. 
3. Jeans, S., Williams, G. L., \& Stephenson, B. M. (2007). Migration after open mesh plug inguinal hernioplasty: a review of the literature. The American surgeon, 73(3), 207-209.

4. Eklund, A., Rudberg, C., Smedberg, S., Enander, L. K., Leijonmarck, C. E., Österberg, J., \& Montgomery, A. (2006). Short- term results of a randomized clinical trial comparing Lichtenstein open repair with totally extraperitoneal laparoscopic inguinal hernia repair. British Journal of Surgery: Incorporating European Journal of Surgery and Swiss Surgery, 93(9), 1060-1068.

5. Lichtenstein, I. L., Shulman, A. G., Amid, P. K., \& Montllor, M. M. (1989). The tension-free hernioplasty. The American Journal of Surgery, 157(2), 188-193.

6. Hasegawa, S., Yoshikawa, T., Yamamoto, Y., Ishiwa, N., Morinaga, S., Noguchi, Y., ... \& Rino, Y. (2006). Long-term outcome after hernia repair with the prolene hernia system. Surgery today, 36(12), 1058-1062.

7. Schmedt, C. G., Sauerland, S., \& Bittner, R. (2005). Comparison of endoscopic procedures vs Lichtenstein and other open mesh techniques for inguinal hernia repair: a meta-analysis of randomized controlled trials. Surgical Endoscopy and Other Interventional Techniques, 19(2), 188199.

8. Robinson, T. N., Clarke, J. H., Schoen, J., \& Walsh, M. D. (2005). Major mesh-related complications following hernia repair. Surgical Endoscopy and Other Interventional Techniques, 19(12), 1556-1560.

9. Bay- Nielsen, M., \& Kehlet, H. (2008). Anaesthesia and post- operative morbidity after elective groin hernia repair: a nation- wide study. Acta Anaesthesiologica Scandinavica, 52(2), 169174.

10. E. Losanoff, Bruce W. Richman, James W. Jones, J. (2001). Inguinal herniorrhaphy with an undetached strip of external oblique aponeurosis: old or new?. The European journal of surgery, 167(11), 877-877.

11. Losanoff, J. E., \& Millis, J. M. (2006). Aponeurosis instead of prosthetic mesh for inguinal hernia repair: neither physiological nor new. Hernia, 10(2), 198-199.

12. McArthur, L. L. (1901). Autoplastic Suture In Hernia, And Other Diastases.-Preliminary Report. Journal of the American Medical Association, 37(18), 1162-1165.

13. Ravitch, M. M., \& Hitzrot, J. M. (1960). The operations for inguinal hernia: I. Bassini, Halsted, Andrews, Ferguson. Surgery, 48(2), 439-442.

14. Desarda, M. P. (2006). Physiological repair of inguinal hernia: a new technique (study of 860 patients). Hernia, 10(2), 143-146.
15. Desarda, M. P. (2003). Surgical physiology of inguinal hernia repair-a study of 200 cases. $B M C$ surgery, 3(1), 2.

16. Carroll, I., \& Curtin, C. M. (2013). Management of chronic pain following nerve injuries/CRPS type II. Hand clinics, 29(3), 401-408.

17. Page, B., Paterson, C., Young, D., \& O'Dwyer, P. J. (2002). Pain from primary inguinal hernia and the effect of repair on pain. British journal of surgery, 89(10), 1315-1318.

18. Aasvang, E., \& Kehlet, H. (2004). Chronic postoperative pain: the case of inguinal herniorrhaphy. British journal of anaesthesia, 95(1), 69-76.

19. Alfieri, S., Amid, P. K., Campanelli, G., Izard, G., Kehlet, H., Wijsmuller, A. R., ... \& Doglietto, G. B. (2011). International guidelines for prevention and management of post-operative chronic pain following inguinal hernia surgery.

20. Grant, A. (2002). Open mesh versus non-mesh repair of groin hernia meta-analysis of randomized trials leased on individual patient data. Hernia, 6(3), 130-136.

21. Horstmann, R., Hellwig, M., Classen, C., Röttgermann, S., \& Palmes, D. (2006). Impact of polypropylene amount on functional outcome and quality of life after inguinal hernia repair by the TAPP procedure using pure, mixed, and titaniumcoated meshes. World journal of surgery, 30(9), 1742-1749.

22. Paajanen, H. (2007). A single-surgeon randomized trial comparing three composite meshes on chronic pain after Lichtenstein hernia repair in local anesthesia. Hernia, 11(4), 335-339.

23. Staerkle, R. F., Buchli, C., \& Villiger, P. (2009). Patient satisfaction, hernia recurrence rate, and chronic pain 10 years after endoscopic total extraperitoneal inguinal hernia repair. Surgical Laparoscopy Endoscopy \& Percutaneous Techniques, 19(5), 405-409.

24. Situma, S. M., Kaggwa, S., Masiira, N. M., \& Mutumba, S. K. (2009). Comparison of Desarda versus modified Bassini inguinal Hernia repair: a randomized controlled trial. East and Central African Journal of Surgery, 14(2), 70-76.

25. Desarda, M. P., \& Ghosh, A. (2006). Comparative study of ppen mesh repair and Desarda's no-mesh repair in a District Hospital in India. East And Central African Journal of Surgery, 11(2), 28-34.

26. Desarda, M. P. (2007). A new technique of inguinal hernia repair-neither similar to nor modification of Desarda's repair. J Indian Med Assoc, 105(11), 654.

27. Desarda, M. P. (2008). No-mesh inguinal hernia repair with continuous absorbable sutures: A dream or reality? (a study of 229 patients). Saudi journal of gastroenterology: official journal of the Saudi Gastroenterology Association, 14(3), 122. 